\title{
Finite Element Analysis of Variable Thickness Disc Wheel Rim for Weight Optimization
}

\author{
Nilesh Kumar Popatlal Kankariya ${ }^{(1)}$ \\ ME (Design) Mechanical Engineering \\ JSPM's -R.S College of Engineering, \\ Pune, Maharashtra.
}

\author{
Prof. Shailesh S. Pimpale (2) \\ Mechanical Engineering Department \\ JSPM's - R.S. College of Engineering, \\ Pune, Maharashtra.
}

\author{
Dr. Subim N. Khan ${ }^{(3)}$ \\ Mechanical Engineering Department \\ JSPM's -R.S College of Engineering, \\ Pune, Maharashtra.
}

\begin{abstract}
The objective of this paper is to introduce light weight wheel rim by opting variable wall thickness of wheel disc without affecting its key functions and life. Wheel rim 3D model prepared in Pro-E software. Linear static structural analysis of wheel rim were performed in FEM - ANSYS software to determine stress level at various loading conditions, given boundary conditions to optimize disc thickness, weight, cost of wheel rim. The results of the FEA analysis to validate with the experimental test results.
\end{abstract}

Keywords-Wheel rim; Wheel rim disc; Variable thickness; Pro-E design; FEA.

\section{INTRODUCTION}

A wheel rim is a highly stressed component in an automobile that is subjected to bending and torsional loads. Since it is subjected to high stresses and demand of long life, light in weight, which it becomes very important to select right material and manufacturing process in rim design. There are competitions among materials and manufacturing processes due to cost performance and weight. The main components of the wheels \& tire system aggregates is the wheel rim. Performance of wheel rim directly affects the vehicle performance and safety. Wheel rim size selection is based on tire size used in vehicle, It has standard catalogue - JATMA which recommends standard wheel rim size accordingly.

Tata 1109 ILCV Vehicle recommended wheel rim size is $6.5 \times 20$ is as per JATMA standard for $8.25 \mathrm{R} 20$-14PR tire size. Wheel rim was taken for weight optimization analysis and experimental study purpose refer below three piece wheel rim figure no. 1

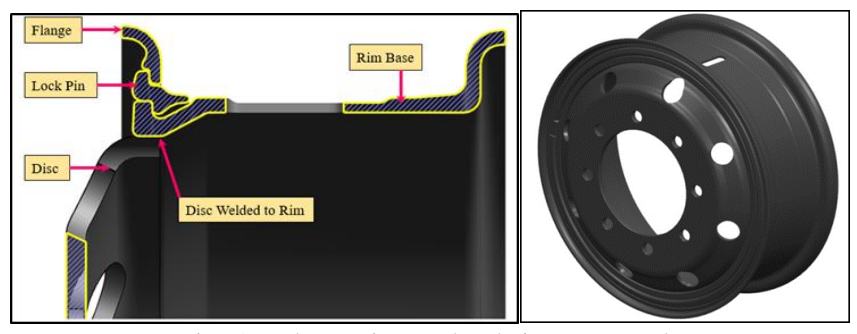

Fig. 1 : Three piece wheel rim nomenclature
In this perspective expecting wheel rim design with significant mass reduction without compromise in its function and performance. The above wheel rim weight can be reduced by recognizing various stress regions and corresponding changes in wheel rim design. Rim material can be removed wherever is lower stress region and has low vehicle load effect.

\section{PROBLEM STATEMENT}

Currently Tata 1109 ILCV vehicles recommended wheel rim size has higher weight, cost which need to be analyze and optimized under finite element analysis. Analysis of wheel rim to determine the material removal area, changes in von misses stresses and deformation for current and modified rim design within given boundary condition to gain significant advantages for lighter mass vehicle wheels.

\section{METHODOLOGY}

The methodology involves technology for performing the designing and analyzing of the object.

- Design and modeling of three piece wheel rim

- Dimension specification

- $\quad$ Analysis by ANSYS

- Analysis to perform at various load condition on existing and modified rim design.

- $\quad$ Analysis of wheel rim under boundary condition to obtain deformation and von misses stresses of model.

- $\quad$ Obtained optimized wheel rim and compare with existing model.

\section{CAD DESIGN}

Design Input parameters of TATA 1109 ILCV Vehicle

Existing Three Piece Wheel Rim Design:

- Vehicle Tire size : 8.25 R20 - 14 PR

$\{$ Front - 2, Rear - 4, Spare - 1\}

- Wheel rim mass per wheel $-42.5 \mathrm{~kg}$ 
- Recommended Wheel rim as per ITTAC : 6.5 x 20

- Load on each wheel (rated and overload condition) : $2300 \mathrm{~kg}, 2650 \mathrm{~kg}, 3000 \mathrm{~kg}$

- $\quad$ Material : Rim Rst 37 \& Disc - Yst 38

- Wheel rim disc manufacturing process - Press forming

- $\quad$ Mass of Vehicle - $3960 \mathrm{~kg}$

- Payload on vehicle $-8710 \mathrm{~kg}$

Existing wheel rim CAD design prepared using Pro-E Software.

- $\quad$ Sketcher

- Part design

- Assembly design

- $\quad$ Wireframe and surface design

- $\quad$ Meshing \& analysis by ANSYS software

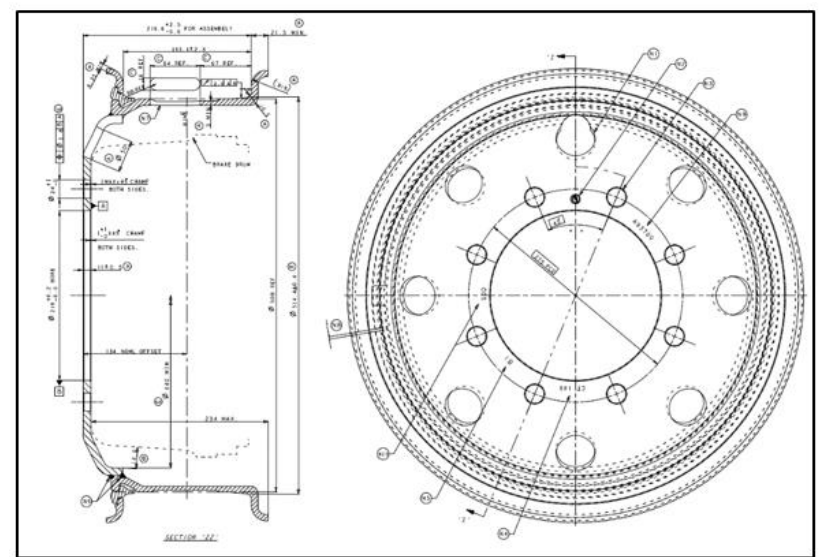

Fig 2 : Existing Wheel Rim 2D Drawing
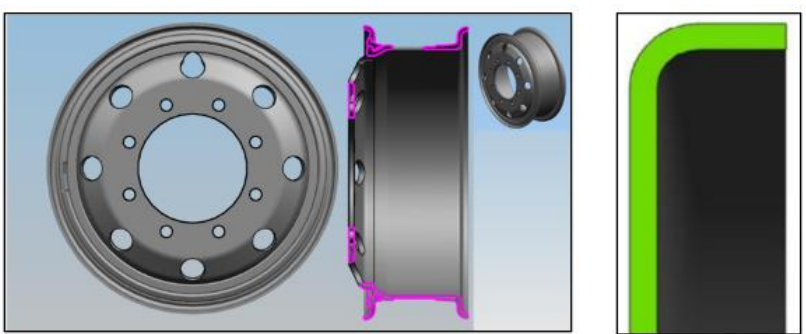

Fig 3 : Existing Wheel Rim 3D Model

\begin{tabular}{|l|c|}
\hline \multicolumn{1}{|c|}{ Specification } & Wheel rim \\
\hline Tyre size & 8.25 R20-14PR \\
\hline Wheel rim Size & $6.5 \times 20$ \\
\hline Rim Thickness in $\mathrm{mm}$ & 6 \\
\hline Rim Material & Rst 37-2 \\
\hline Bolt hole Diameter in mm & $\varnothing 24$ \\
\hline Bolt hole Numbers & 8 \\
\hline Disc Thickness in $\mathrm{mm}$ & 11 \\
\hline Disc Material & Yst 38 \\
\hline Wheel Offset & 134 \\
\hline Wheel Weight in $\mathrm{Kg}$ & 42.4 \\
\hline
\end{tabular}

Table 1: Existing Wheel Rim Specification

\section{OPTIMIZATION SCOPE}

i) Three Piece Wheel Rim Optimization Scope - Design The following are the design changes incorporated to reduce the wheel rim weight, cost and improve its performance:

- Increase in nave thickness to avoid crack initiation in the region due to fretting.

- Variable disc thickness to reduce weight and cost of rim.

- Increased cold working effect on the product.

- Optimized brake drum clearance thru variable thickness.

- Wheel rim flow forming manufacturing process.

\begin{tabular}{|l|c|c|}
\hline \multicolumn{1}{|c|}{ Specification } & Existing Design & Modified Design \\
\hline Wheel Size & Same as existing & Same as existing \\
\hline Rim Thickness in $\mathrm{mm}$ & 6 & Optional \\
\hline Rim Material & Rst $37-2$ & Optional \\
\hline Bolt hole Diameter in $\mathrm{mm}$ & $\varnothing 24$ & Same as existing \\
\hline Bolt hole Numbers & 8 & Same as existing \\
\hline Bolt hole PCD in $\mathrm{mm}$ & 275 & Same as existing \\
\hline Vent hole Numbers & 144 & Same as existing \\
\hline $\begin{array}{l}\text { Total Ventilation Area in } \\
\text { cm }\end{array}$ & 11 & Minimum 144 \\
\hline Disc Thickness in mm & Yst 38 & Optional \\
\hline Disc Material & 134 & Yst 38 \\
\hline Wheel Offset & 3000 & Same as existing \\
\hline Wheel Load in Kg & 42.4 & Target 36 kg / Per wheel \\
\hline Wheel Weight in Kg & & \\
\hline
\end{tabular}

Table 2: Wheel Rim Design Optimization Scope and Space 
ii) Three Piece Wheel Rim Optimization Scope -Process

- The goal is to flow form and optimize disc weight.

- Increase disc material yield strength

- Process compress disc material to increase its hardening by cold working, hence we can get higher yield, tensile strength and thinner thickness

- Reduce the rim weight without compromising the performance.

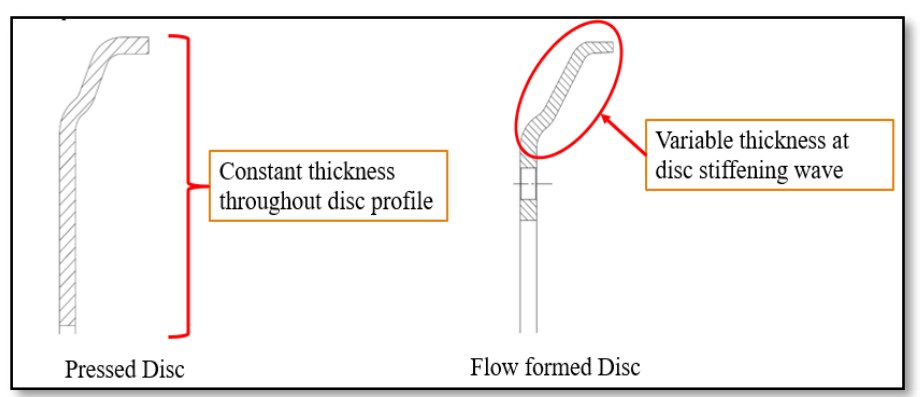

Fig 4: Wheel Rim Process Optimization Scope

\section{OPTIMIZED CAD DESIGN}

\section{Modified Three Piece Wheel Rim Design}

As per above table no. 2 and figure no. 4 where wheel rim design changes and process improvement were done for optimization, cad data has been modified in Pro-E.

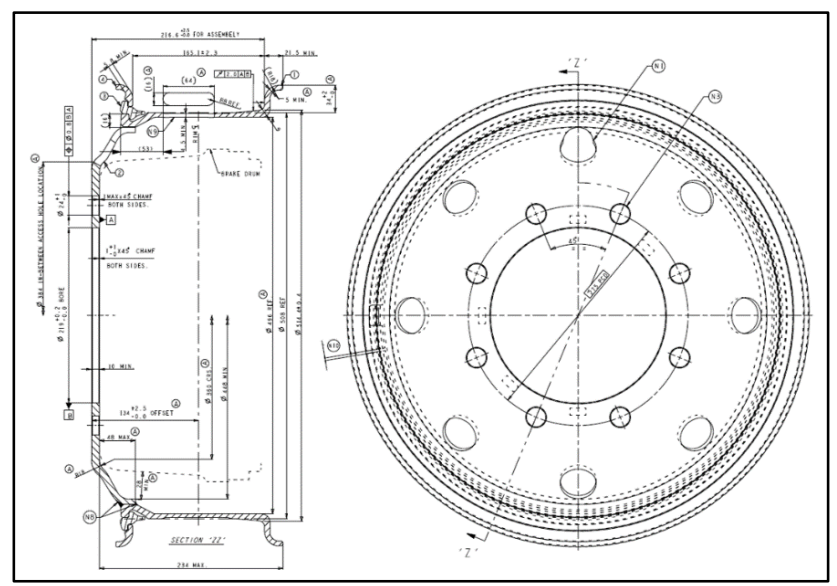

Fig 5: Modified Wheel Rim 2D Drawing

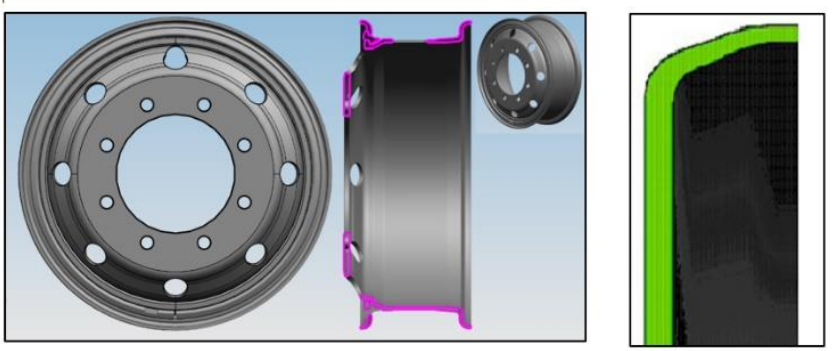

Fig 6: Modified Wheel Rim 3D Model

\begin{tabular}{|l|c|c|}
\hline \multicolumn{1}{|c|}{ Descreption } & Equivalent material & Weight in Kg \\
\hline 6.5HDX20 RIM & DIN17100 Rst 37-2 & \multirow{2}{*}{$28.0 \pm 2.5 \%$} \\
\hline WHEEL DISC & Yst 38 & \\
\hline LOCKRING & DIN17100 st $60-2$ & $4 \pm 2.5 \%$ \\
\hline FLANGE & DIN17100 st $60-2$ & $4 \pm 2.5 \%$ \\
\hline $\begin{array}{l}\text { ASSEMBLY (Rim base with } \\
\text { disc + Lockring + Flange) }\end{array}$ & NA & $36 \pm 2.5 \%$ \\
\hline
\end{tabular}

Table 3: Wheel Rim material Specification

\begin{tabular}{|l|c|}
\hline \multicolumn{1}{|c|}{ Specification } & $\begin{array}{c}\text { Modified Wheel rim } \\
\text { Design }\end{array}$ \\
\hline Tyre Size & $8.25 \mathrm{R} 20-14 \mathrm{PR}$ \\
\hline Wheel Size & $6.5 \times 20$ \\
\hline Rim Thickness in $\mathrm{mm}$ & Rst 37-2 \\
\hline Rim Material & $\varnothing 24$ \\
\hline Bolt hole Diameter in mm & 8 \\
\hline Bolt hole Numbers & Variable \\
\hline Disc Thickness in $\mathrm{mm}$ & Yst 38 \\
\hline Disc Material & 134 \\
\hline Wheel Offset & 3000 \\
\hline Wheel Load in Kg & Target 36 kg / Per wheel \\
\hline Wheel Weight in Kg &
\end{tabular}

Table 4: Modified Wheel Rim Specification

Optimized wheel rim design proposal made based on Finite element analysis (FEA). Wheel disc thickness increased at the region identified to have higher stress and gradual reduction of material thickness at lower stressed regions. The modification in the design is shown in the Fig. 5 and 6.

Following design changes to be incorporated to reduce rim weight and also simultaneously improve its performance:

- Increase in nave thickness to avoid crack initiation in the region due to fretting

- Variable disc thickness to reduce weight, cost of the product and new process of variable disc increased cold working effect on the product.

- Improvement in brake drum clearances.

- Adaptation of Rim Flow Forming manufacture process

- $\quad$ Flange Shape Optimization

\section{ANALYSIS}

TATA 1109 ILCV wheel rim specification 6.5x20 design and modeled in 3D using Pro-E software. 3D model imported to ANSYS Workbench for further analysis such as cornering effect thru FEA and compare stress analysis at different loading condition. 
$\bullet$

\section{Geometry of Three Piece wheel rim}

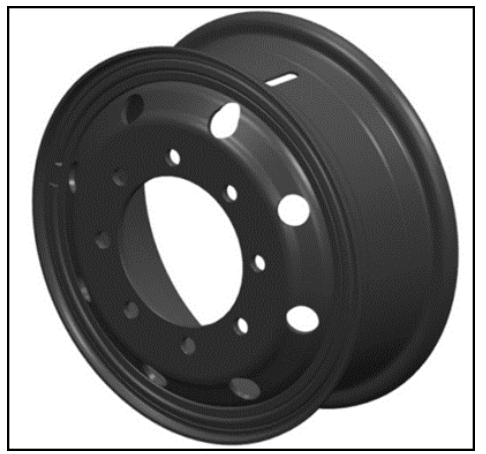

Fig 7: Three Piece Wheel Rim Geometry

\section{- Boundary Condition}

- Wheel, adaptor, bolts modeled, assembled.

- $\quad$ Tetrahedral mesh used for the wheel and hub.

- $\quad$ Cornering load applied.

- $\quad$ Rim flange fixed in all DOF.

- Results viewed in the post processor.

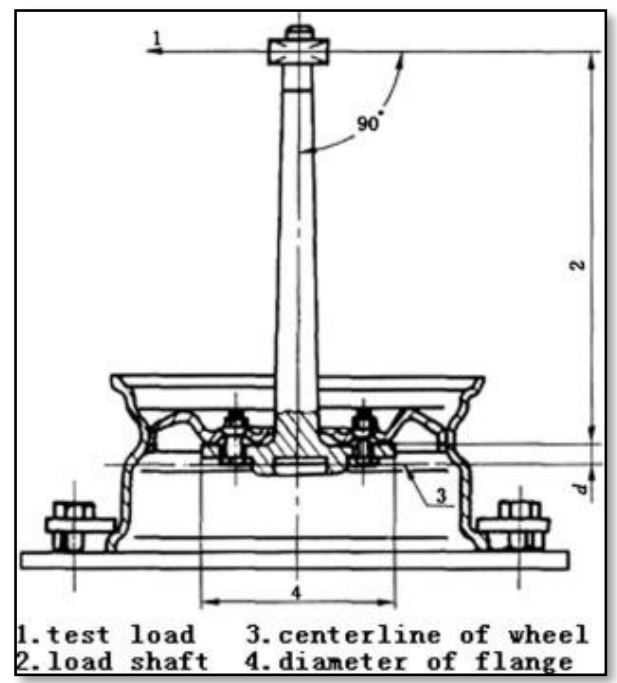

Fig.8 : Boundary Condition

\section{- Meshing and Boundary Condition for Wheel rim}

Meshing and boundary condition applied in ANSYS to reduced degree of freedom from infinite to finite with the help of discretization or meshing (Nodes \& Elements). Wheel rim flange were fixed and cornering load applied.

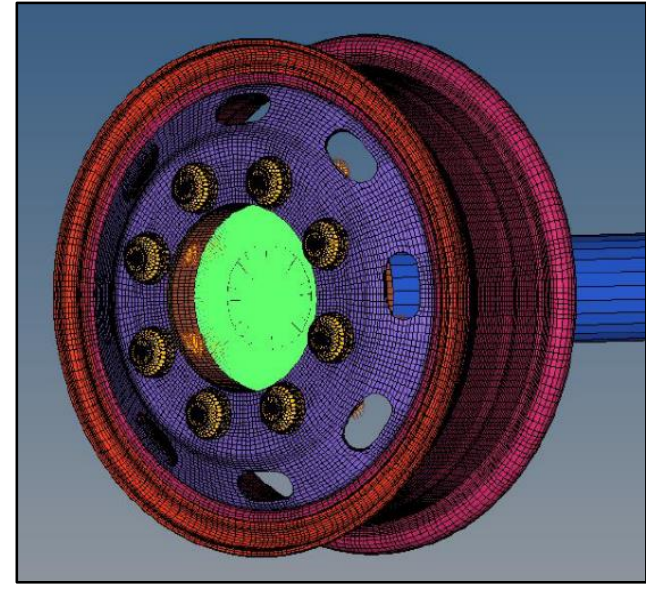

Fig. 9: Meshing and Boundary Conditions

\section{- Wheel Rim Stress Distribution and Analysis}

The wheels were loaded due to cornering and lateral effect and same was simulated at various test conditions and accordingly results are obtained. FEA evaluated displacement at each node of wheels according to the initial boundary conditions from which the strain can be calculated and then using Hooke's law the stress at that point can be calculated using the Young's modulus of the material of the wheel.

\section{- $\quad$ Equivalent Stress Results}

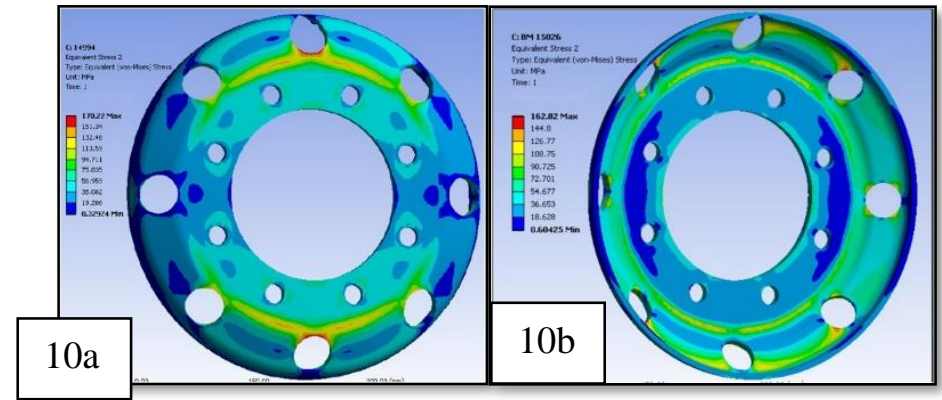

Fig 10 (a) Stress plot with uniform thickness wheel disc at 30KN Fig 10 (b) Stress plot with variable thickness wheel disc at 30KN

\section{RESULTS}

The following table no. 5 shows comparative stress analysis results of existing as well as modified three piece wheel rim design with various load cases $\&$ boundary conditions.

- Comparative Stress Analysis Results

\begin{tabular}{|c|c|c|c|c|c|}
\hline $\begin{array}{c}\text { VON MISES } \\
\text { STRESS (MPa) }\end{array}$ & $2300 \mathrm{Kg}$ & $2650 \mathrm{Kg}$ & $3000 \mathrm{~kg}$ & $\begin{array}{c}\text { YIELD } \\
\text { STRENGTH }\end{array}$ & $\begin{array}{c}\text { WEIGHT } \\
\text { Kg }\end{array}$ \\
\hline Existing Design & 130 & 150 & 170 & 380 & 42.4 \\
\hline $\begin{array}{c}\text { Modified } \\
\text { Design }\end{array}$ & 125 & 143 & 162 & 380 & 36 \\
\hline
\end{tabular}

Table 5: Comparative Stress Analysis Results 


\section{SUMMARY}

- The FEA comparative results shown in table no. 5 that the variable thickness disc had lower or equivalent stresses value as than existing wheel rim with uniform thickness.

- $\quad$ Analysis shows the uniform thickness disc had a stress value of $170 \mathrm{MPa}$ whereas the variable thickness disc wheel had a stress value of $162 \mathrm{MPa}$.

- $\quad$ Peak stress is at the vent hole region for existing wheel rim with the thickness of $11 \mathrm{~mm}$, by introducing variable thickness about $10 \mathrm{~mm}$ at same location the stress level can be brought down to $5 \%$.

- Variable disc thickness achievable with an advanced manufacturing technique called the flow form / spinning process. This process facilitated the vent hole position in a single plane with adequate ventilation area and the reduction in stresses was also noticed.

- With modified wheel rim design weight is reduced from $42.4 \mathrm{~kg}$ to $36 \mathrm{~kg}$ per wheel, which is approximately $16 \%$ without affecting functional requirement.

\section{REFERENCES}

[1] S.Chaitanya and B.V.Ramana Murty "Mass Optimization of Automobile Wheel Rim", IJETT, 2015, 26 (3), pp 169-173.

[2] Sourav Das "Design and Weight Optimization of Aluminium Alloy Wheel", IJOSRP, 2014, 4(6), pp1-12

[3] R. Muthuraj, R.Badrinarayanan and T.Sundararajan, "Improvement in the wheel Design using realistic Loading Conditions - FEA and Experimental Stress Comparison", SAE Technical Paper Series 2011-28-0106

[4] R. Muthuraj and Dr.T.Sundararajan, "The Forged Hybrid Wheel for Commercial Vehicles, A Robust Design for Augmented Product Service and Performance", SAE Technical Paper Series 2015-26-0068.

[5] Haruo Nagatani \& Tsuyoshi Niwa "Application of Topology Optimization and Shape Optimization for Development of HubBearing Lightening”, TN Technical Review 73, 2015, pp14-19

\section{Reference Standard}

[6] IS: 9438-Performance Requirements and Methods of test for Wheels/Rims for Trucks and Buses standard, 2000.

\section{Reference Book}

[7] Reference Manual-ITTAC, 2014 